
Indícios dos modos de producção fotojornalísticos nos blogs de fotografia dos diários de maior circulação do Brasil

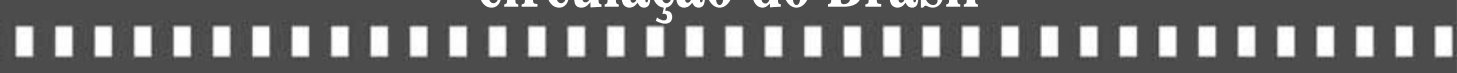

\author{
Julia Capovilla Luz Ramos
}

Jorge Pedro Sousa

Artigo recebido em: 18/07/2016

Artigo aprovado em: 03/03/2018 


\title{
Indícios dos modos de produçãa fotojornalísticos nos blogs de fotografia dos diários de maior circulação do Brasil
}

Indications of the photojournalistic production methods in the photo blogs of Brazilian greatest circulation diaries

\author{
Julia Capovilla Luz Ramos* \\ Jorge Pedro Sousa"*
}

\begin{abstract}
Resumo: Mudanças na prática e na produção fotográfica desde a adesão das tecnologias digitais pelas empresas jornalísticas fez com que muitos profissionais da imagem acreditassem em uma crise sem precedentes. Para outros, as novas rotinas produtivas se configuram como a possibilidade de refletir sobre a pratica da cobertura fotojornalistica e estabelecer as bases da atividade para si e para o grupo. Neste sentido, os blogs de fotografia dos jornais de maior circulação do Brasil aparecem como espaços que possibilitam a circulação destas reflexões sobre os modos de produção noticiosa diária, seja em textos ou por meio das imagens.
\end{abstract}

Palavras-chave: Fotojornalismo. Rotinas produtivas. Blogs de fotografia.

Abstract: Changes in practice and in the photographic production since the accession of digital technologies by the newspaper companies made many image professionals believe in an unprecedented crisis. For others, the new production routines are configured as the ability to reflect on the practice of photojournalistic coverage and establish the bases of the activity for themselves and the group. In this sense, the photo

*Jornalista e doutoranda em Comunicação do PPG da Unisinos, RS. Bolsista CAPES.

**Professor catedrático e investigador da Universidade Fernando Pessoa (Porto/ Portugal) e do Centro de Investigação Media \& Jornalismo. 
blogs of the greatest circulation diaries in Brazil appear as spaces that allow circulation of these reflections on the ways of daily news production, either in text or through images.

Keywords: Photojournalism. Productive routines. Photo Blogs.

Em sua "Teoria da Estruturação", Anthony Giddens (2003) identifica a potência dos sujeitos enquanto agentes sociais de entenderem o que fazem enquanto fazem, condição indispensável para a realização de determinadas atividades num espaço-tempo. Segundo ele, "todo o ator social competente, [...] é um teórico social no nível da consciência discursiva e um especialista metodológico nos níveis da consciência prática e discursiva" (GIDDENS, 2003, p. 21).

A diferenciação proposta por Giddens (2003) entre consciência prática e consciência discursiva, englobaria desde a simples percepção dos afazeres até a crítica constante sobre as próprias ações. Primeiramente, os sujeitos refletiriam sobre como agem e porquê agem, num processo de autoconhecimento. Essa seria a fase da "consciência prática". Já na fase da "consciência discursiva", tais indivíduos passariam a expressar de forma concreta as condições, possibilidades e limites das próprias ações.

Se nos voltarmos ao universo jornalístico, podemos notar que o discurso proveniente dos agentes das práticas tem ganhado cada vez mais os espaços midiáticos, funcionando ora como estratégia de ampliação da audiência; ora como operação de legitimação do campo. Tal recurso vem sendo chamado por autores como Fausto Neto (2010) de "auto-referencialidade", e definido como a capacidade de atestar a existência do campo e fortalecer suas fronteiras, instituindo regras sobre as quais se apoiam as atividades jornalísticas, não só para que sirvam de parâmetro aos colegas de profissão, mas para estabelecer uma espécie de "novo" contrato com o público. "Por intermédio deles [os jornalistas], 
e pelo fato de serem destacados personagens singulares de um sistema produtivo, é que se consagra a importância de uma prática social" (FAUSTO NETO, 2010, p. 124-125), atestando, por essa razão, que o saber jornalístico não deve permanecer circunscrito às normas dos manuais de redação.

Esse tipo de construção enunciativa sobre si também traz em seu bojo o reforço da existência de uma comunidade interpretativa' (ZELIZER, 2000), cuja a ideia de pertencimento a um grupo profissional aparentemente coeso e estável se deve, justamente, ao entendimento das lógicas da produção através de sua explicitação. Neste sentido, enquanto a auto-referencialidade seria o procedimento responsável por desmistificar a atividade jornalística; o fortalecimento do ethos profissional se ligaria a interpretação das práticas por uma comunidade. Mesmo sentido encontramos em Soloski (1993), que vai atrelar o reconhecimento de uma atividade como profissão aos controles de uma "base cognitiva" comum entre os sujeitos que dela participam. Para tanto, é preciso que haja, conforme o autor, um conjunto de conhecimentos suficientemente estáveis ministrados por todos os profissionais, além da garantia de que o público os considerem os únicos indivíduos capazes de fornecer tais serviços. Sendo assim, ao assegurar o controlo sobre a base cognitiva da profissão, a profissão também estabelece um monopólio no mercado profissional.

Sendo a prática fundamental a qualquer realização humana, as condições que as tornam naturalizadas merecem ser explicitadas. Para Foucault (1986, p. 136), todas as práticas são discursivas e deixam transparecer um conjunto de regras anônimas e históricas capazes de condicionar as ações dos sujeitos ao mesmo tempo em que são recriadas por eles, num movimento contínuo de autorreflexão e

1 Conforme já sublinhamos em obra anterior (SOUSA, 2002, p. 9), foi T.R. Lindlof (1998) quem, pela primeira vez, teorizou sobre as "comunidades interpretativas". Para ele, as práticas de comunicação mediada dão lugar a comunidades que procedem de determinadas formas em função de convenções específicas. Posteriormente, o conceito foi retomado e trabalhado por Barbie Zelizer. 
monitoramento reflexivo dos diferentes atores sociais.

Face ao exposto, é objetivo deste artigo, portanto, identificar os modos utilizados pelos repórteres fotográficos para refletirem sobre suas atividades e extrair regras que confiram autonomia e especificidade ao campo da fotografia jornalística a partir de algumas imagens e textos publicados nos blogs de fotografia dos jornais brasileiros de grande circulação². São eles, o Fotoglobo, do jornal carioca $O$ Globo; o Olhar sobre o Mundo, do diário paulista $O$ Estado de São Paulo; o FocoBlog, do periódico rio-grandense Zero Hora; o Diário da Foto, o Diário Gaúcho; e o FotoCorreio, do Correio do Povo, estes dois últimos também do Rio Grande do Sul.

Parece-nos pertinente dizer que a amostra selecionada para análise no presente artigo, embora arbitrária e não probabilística, corresponde à eleição de exemplos-padrão sugerida por autores como Wimmer e Dominick (1996, p. 176). Em nosso entendimento, são imagens e comentários sobre as práticas fotojornalisticas que dão pistas das rotinas produtivas de eventos notáveis, como guerras e catástrofes, além de apresentarem os bastidores do dia-a-dia profissional dentro e fora das redações, a fim de tentar extrair-lhe regras.

\section{Foco nas práticas}

Assim como o jornalismo requer rotinas produtivas, o fotojornalismo seria o campo prático por excelência.

2 Em novembro de 2012, eram cinco, dos 10 jornais de maior circulação no Brasil, que possuíam blogs de fotografia, segundo dados do Instituto Verificador de Circulação (IVC): o Fotoglobo; o Olhar sobre o Mundo; o FocoBlog; o Diário da Foto; e o Fotocorreio. O Fotoglobo, do jornal O Globo, do Rio de Janeiro, porém, anunciou sua "saída" da blogosfera no dia 30 de abril de 2013. Apesar de o endereço eletrônico manter-se ativo, o blog de fotografia Olhar sobre o Mundo, do jornal $O$ Estado de São Paulo, também teve sua última publicação em 25 de janeiro de 2014. Em março de 2015, mais uma baixa: o blog Diário da foto, do jornal Diário Gaúcho deixou de ser atualizado. Somente dois únicos blogs que se mantêm efetivamente ativos até hoje - FocoBlog (Zero Hora) e FotoCorreio (Correio do Povo). 
Particularmente, os exemplos abaixo mostram-se relevantes a partir do momento em que se centram nas condições adversas enfrentadas pelos fotógrafos durante a cobertura de guerras e conflitos. No dia 25 de outubro de 2010, por exemplo, o repórter Rodrigo Lopes publicou no FocoBlog a imagem do fotógrafo João Silva "em ação" (Figura 1). A imagem mostra João sobre um terreno árido e aparentemente deserto, com a câmera em frente ao rosto. O que denuncia seu modo de trabalho no front é, justamente, a posição de suas pernas. Ou seja, ele fotografa enquanto caminha, já que não há tempo nem segurança para escolher o melhor ângulo neste tipo de situação. A imagem serve, todavia, de gancho para a notícia de que João Silva havia acabado de sobreviver à explosão de uma mina na cidade de Kandahar, no Afeganistão, no último sábado, mesmo acidente que o fez, justamente, perder as pernas.

O texto que acompanha a imagem é permeado de diretrizes profissionais, formulando uma espécie de "código de conduta" para a cobertura jornalística em zonas de conflito. Redigido pelo repórter Rodrigo Lopes, que esteve no Líbano em 2006 e em outros locais conflagrados, como o Haiti, o texto salienta que "mesmo ferido pela explosão e com hemorragia interna, João fez o que todos nós, colegas de profissão, esperávamos que fizesse: continuou a fotografar". Além de servir como elo de identificação entre o repórter e o fotógrafo, ao tentar reunir numa mesma categoria/ classe todos os correspondentes de guerra, tanto as palavras como a imagem servem para reforçar o ideário da profissão.

Tocado pelo o que os colegas de profissão enfrentam durante o trabalho em zonas conflituosas, também o editor de fotografia do jornal Zero Hora, Jefferson Botega, publicou no FocoBlog em 18 de março de 2011 a imagem dos fotógrafos Lynsey Addario e Jhon Moore (Getty Image); Tyler Hicks (The Times Photo); Paul Conroy

3 Repórter fotográfico do The New York Times e responsável pela cobertura de conflitos na África, nos Bálcãs e no Iraque. Junto com Greg Marinovich, Ken Oosterbroek e Kevin Carter formam o chamado Clube do Bangue-Bangue ao realizarem a cobertura da guerra entre facções negras, travada todos os dias na África do Sul entre 1990 e 1994. 
66 Indícios dos modos de produção fotojornalísticos nos blogs de fotografia dos diários de maior circulação do Brasil

(Reuters); Holly Pickett e Philip Poupin (freelancers) fugindo de bombardeio próximo a refinaria Ras Lanuf, na Líbia (Figura 2).

Figura 1 - Post "A Guerra Cobra Seu Preço"

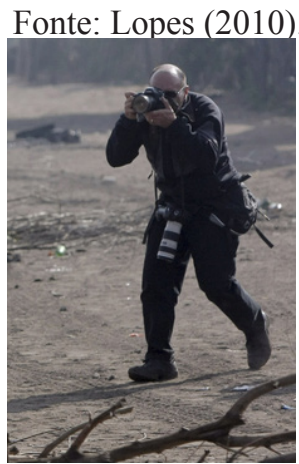

Figura 2 - Post "Fotógrafos e Cinegrafistas Desaparecidos na Líbia" Fonte: Botega (2011a).

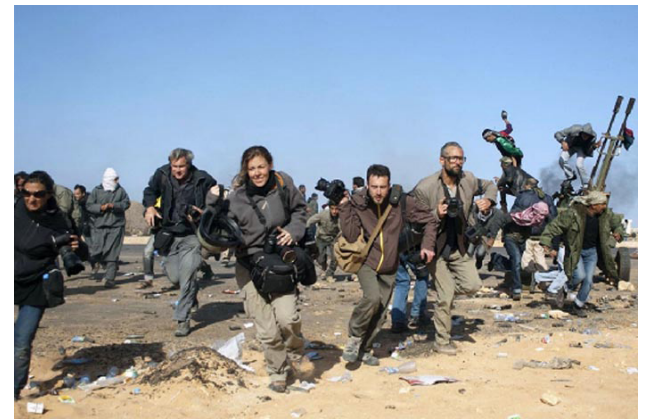

Ainda, no dia 2 de outubro de 2011, o blog Olhar sobre o mundo relembrou o incidente que ocasionou a perda da audição do fotojornalista Philip Blenkinsop após a explosão de uma bomba na Tailândia (Figura 3).

Figura 3 - Post "Testemunhas Oculares da História" 
Fonte: Olhar sobre o Mundo (2011).

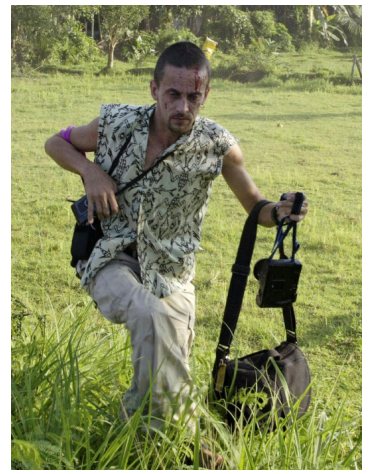

Embora os flagrantes acima deixem evidente o grau de imprevisibilidade deste tipo de evento, os semblantes pouco tensos dos fotógrafos parecem apontar justamente o contrário: para os embedded (embutidos, no jargão jornalístico-militar), que acompanham tão de perto os perigos dos conflitos armados, este tipo de situação não afeta, ou pelo menos não deveria afetar, o resultado de seus trabalhos. Afinal, segundo Botega, eles estão "onde os bons profissionais devem estar: no epicentro dos dramas humanos" (TP FocoBlog).

Outra marca recorrente identificada nestas imagens é o corpo do fotógrafo em movimento, seja em meio a explosões ou em confronto com policiais (Figura 4). O movimento é usado amplamente na fotografia de imprensa, devendo o fotógrafo, para conseguir tal recurso, utilizar uma velocidade lenta de obturação. Porém, ao se tornar protagonista da ação, o movimento deixa de ser apenas um recurso fotográfico e passa a se relacionar de forma direta com o modelo idealizado do fotógrafo profissional, inspirado pela máxima de Robert Capa: "se a foto não for boa é porque não estás suficientemente perto". Neste sentido, o fotógrafo deve deslocar-se constantemente para chegar próximo ao acontecimento, nem que para isso sacrifique a própria vida. É isso que se espera dele; é isso que ele mesmo almeja. A postagem em comemoração ao "dia do 
repórter fotográfico" feita por Natália Russo, na época integrante da equipe de fotografia do jornal O Estado de São Paulo, em 2 de outubro de 2011 no blog Olhar Sobre o Mundo, parece assentarse em tais premissas. A fotógrafa apresenta inicialmente sua visão sobre a atividade profissional com o seguinte texto:

Seja sozinho, ou em meio a dezenas buscando a melhor imagem, seja esperando o acontecimento do século ou simplesmente marcando a delicadeza de um gesto, o repórter fotográfico tem um vínculo inquebrável com a informação. São sempre vistos em ação com suas enormes máquinas e objetivas, mirados nos gabinetes ministeriais ou nos campos mais inimagináveis. Em meio à angústia, à dor, ao mórbido. Tudo isso passa a ser conhecido graças ao fotojornalista. Poder ser considerado intruso é só uma parte do trabalho. A outra, apresenta ao mundo a figura que tenta retratar também a face não convencional do mundo. Amados ou odiados, mas engajados. Eles são, como diria o famigerado slogan do emblemático Repórter Esso: as testemunhas oculares da história. E hoje, 2 de setembro, as câmeras voltam-se para quem diariamente estão por trás: o próprio fotojornalista. São eles, os aniversariantes de hoje, que mostram ao mundo tudo, até mesmo aquilo não seja coisa de capa. Fotógrafo não faz demagogia, fotógrafo faz fotografia!

Após a reflexão, Russo publica um mosaico com mais de 75 fotos, cuja algumas reproduzimos abaixo (Figura 4); elas apontam para a vontade em manter paradigmas profissionais historicamente construídos e consolidados através da imagem de seus corpos subjugados pela violência, curvados à procura de proteção, resilientes para o exercício legal da profissão. A circulação desses discursos constantemente reiterados pelo campo dos media e sustentados pelo público, garantem aos fotojornalistas o reconhecimento como as verdadeiras testemunhas oculares da 
história. A aceitação pública do monopólio de uma profissão no mercado não é difícil de alcançar, segundo Soloski (1993, p. 9394), principalmente se a tarefa "mantém um forte ideal de serviço para a sociedade, sendo considerada um bem universal." No caso do fotojornalismo, o ideal não só se justifica, como é considerado um dos pilares da profissão: o direito à informação como acesso à verdade sobre o mundo.

Figura 4 - Post "Testemunhas Oculares da História"

Fonte: Olhar sobre o Mundo (2011).
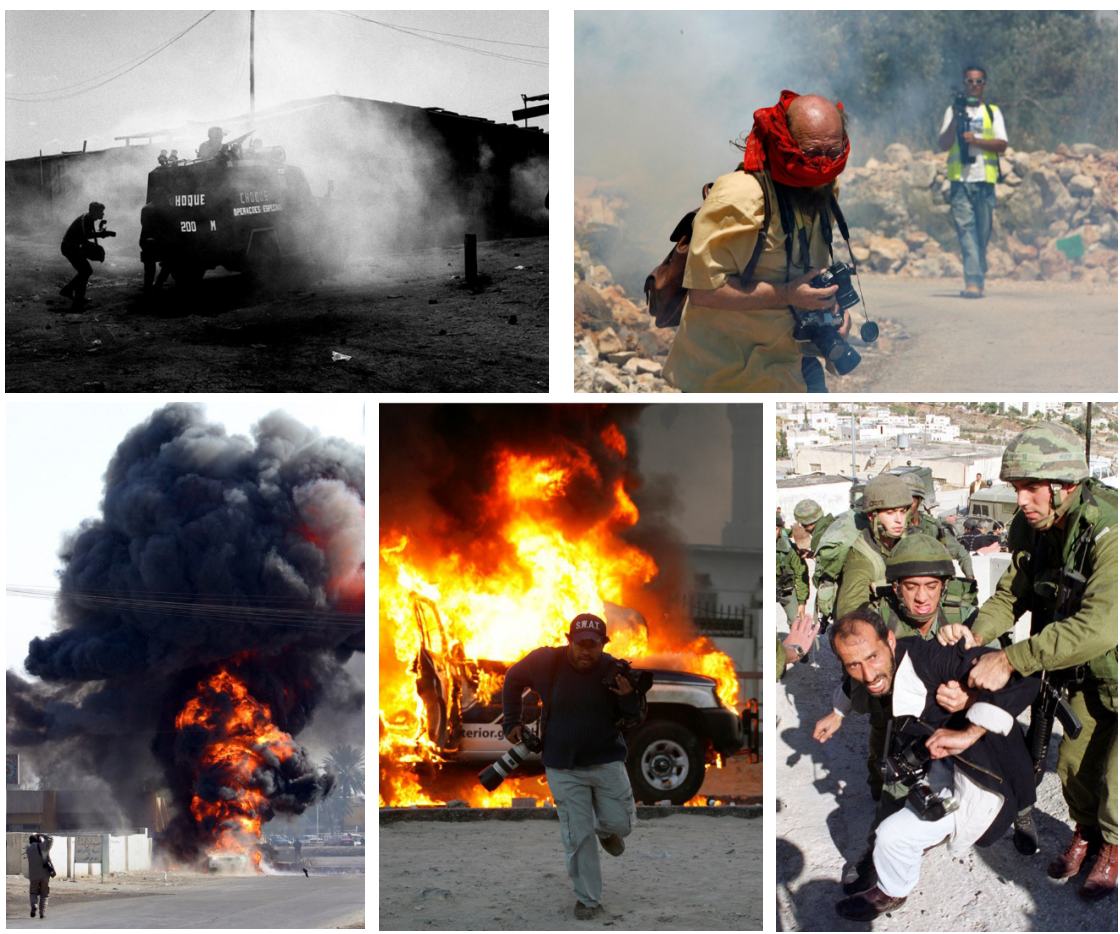
70 Indícios dos modos de produção fotojornalísticos nos blogss de fotografia dos diários de maior circulação do Brasil
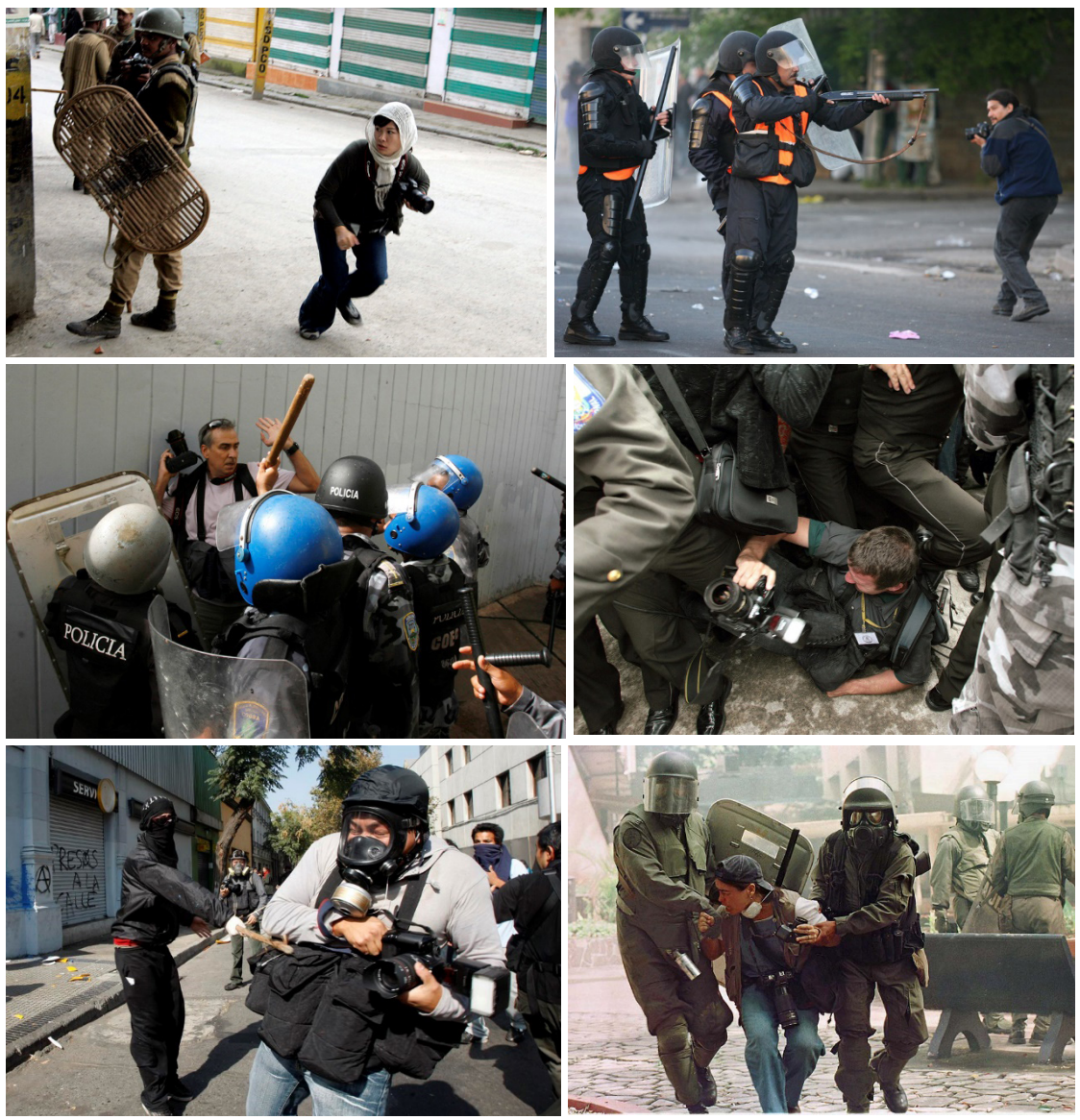

Outras discussões, não menos importantes, que envolvem ética profissional e que permeiam as rotinas fotojornalísticas em situações de conflito, podem ser vistas nos blogs. Fernanda Porto, do site Paraty em Foco (paratyemfoco.com), traz à tona o antigo questionamento: “fazer a foto ou ajudar a vítima?". Para tanto, ilustra o artigo com a foto de Winje Âjijord, disponibilizada pela Associated Press, durante atentado em Oslo (Noruega), que acarretou a morte de mais de 100 pessoas em junho de 2011. A mesma imagem, na qual é possível ver um fotógrafo ajudando policiais a carregar uma mulher ferida foi replicada pelo editor de 
fotografia de Zero Hora no dia 24 de julho de 2011 no FocoBlog (Figura 5). Em tal postagem, o editor aproveita para fazer a seguinte reflexão: "Eu faria o mesmo? Meus colegas fariam o mesmo? Que imagem eu perderia se o fizesse? Que culpa eu carregaria se não o fizesse? Carregaria mesmo culpa?" (BOTEGA, 2011c). Ainda, Jefferson Botega, autor do texto, acresce à postagem outras duas imagens: uma assinada por Thomas Winje, fotógrafo da Agence France Press (AFP), além da reprodução da capa da revista Veja $a_{-}$(Figura 5). Ambas retiram da cena o fotógrafo que ajudou a socorrer a vítima, situação também comentada por Botega: "É o mesmo fotógrafo? Porque a AFP cortou a imagem?". E conclui: "São difíceis as respostas, talvez só passando por isso para saber" (BOTEGA, 2011c).

Figura 5 - Post " Uma Discussão sem Conclusão"
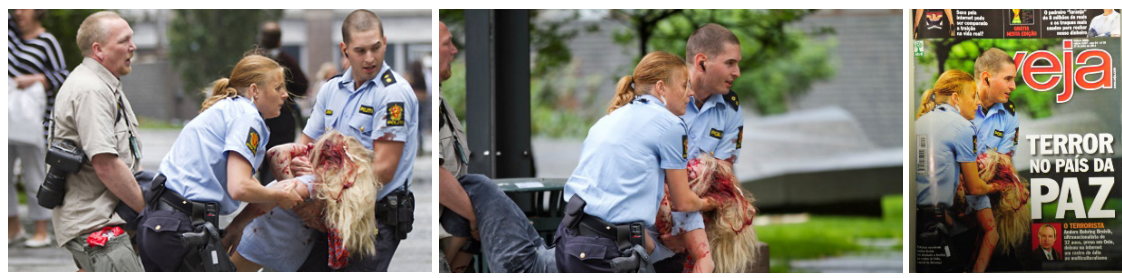

Fonte: Botega (2011c).

Os exemplos de trabalho em situações adversas não param por aí: mais uma vez o responsável pelo FocoBlog, Jefferson Botega, relembra da imagem que o fez "escolher a fotografia como meio de vida". A foto inicialmente publicada na National Geographic mostra, segundo o autor da postagem, "como o fotojornalismo deve ser íntimo e preocupado com o que acontece no mundo em qualquer circunstância”. Na imagem há dois homens com água pela cintura: um carrega uma câmera fotográfica enquanto o outro segura um guarda-chuva. Sobre tal foto, Botega tece o seguinte comentário: "em um momento de muitas discussões a respeito do jornalismo,

4 Revista semanal brasileira de maior circulação nacional publicada pela Editora Abril desde 1968 com tiragem superior a um milhão de cópias. 
72 Indícios dos modos de produção fotojornalísticos nos blogs de fotografia dos diários de maior circulação do Brasil

ela dá uma sensação que, apesar da tecnologia, algumas coisas no modo de fazer jornalismo não mudaram tanto assim" (ALVES, 2011) (Figura 6).

Reforçando a afirmação, em 14 de julho de 2015, o fotógrafo de Zero Hora, Ronaldo Bernardi, publica um autorretrato durante a cobertura das enchentes na cidade de Porto Alegre e região metropolitana (Figura 7). Além de mostrar o fotojornalista caminhando em áreas alagadas, como o colega da National Geograpfic, a legenda da foto também é sugestiva quanto ao imaginário profissional: "aqui podemos ter uma ideia de até onde o fotógrafo precisa ir para trazer as melhores imagens" (BOTEGA, 2015).

Figura 6 - Post "Não vai Mudar Tanto Assim"

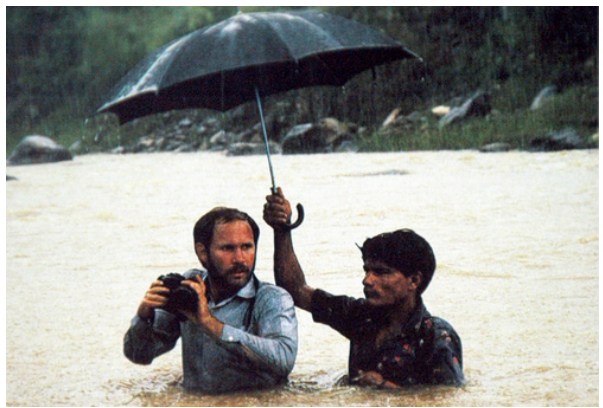

Fonte: Alves (2011).

Figura 7 - Post "Drama das Cheias em Imagens"

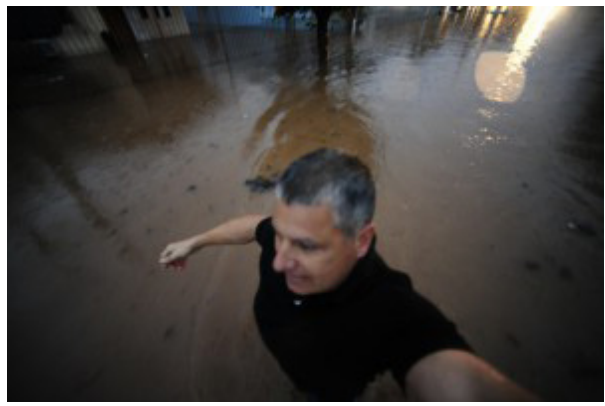


Fonte: Botega (2015).

É também atravessando locais atingidos pelas cheias que o fotojornalista JF Diorio e o repórter Roberto Almeida, do jornal $O$ Estado de São Paulo, finalizaram os trabalhos na expedição Frente Etnoambiental Vale Javari, na região oeste do Amazonas, "depois de quase dois meses embrenhados na mata". No dia 28 de janeiro de 2010, os resultados da expedição foram publicados no blog Olhar sobre o Mundo. Junto ao ensaio, JF Diorio vira suas lentes para os bastidores da reportagem: a segunda imagem da série mostra o jornalista Roberto Almeida trabalhando em seu computador com a cabeça coberta para se proteger "do ataque dos insetos" (Figura 8). Em todas essas figuras, os corpos que atravessam águas e pestes refletem o sacrifício como marca para o bom desempenho da atividade e do alcance à resultados satisfatórios. Como se nos dissessem: um fotojornalista deve ser perseverante ou, pelo menos, tentar fazer a melhor cobertura possível, independente das condições.

Figura 8 - Post "Na Trilha dos Isolados - Parte Ii"
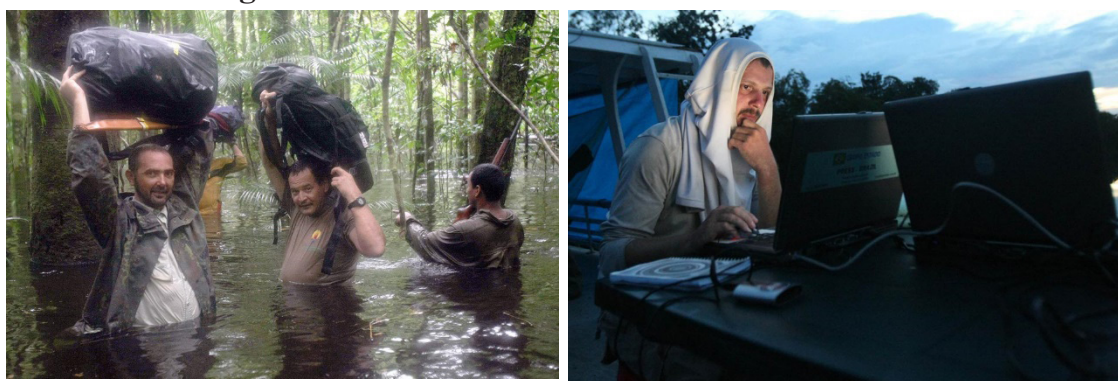

Fonte: Olhar sobre o Mundo (2010a).

Procurando comprovar que a realização do trabalho jornalístico enfrenta inúmeras adversidades, não somente no que diz respeito a aspectos físicos, as postagens a seguir chamam a atenção para as soluções encontradas pelos fotojornalistas frente às restrições técnicas. "Quando a conexão é ruim, improvisa-se", 
74 Indícios dos modos de produção fotojornalísticos nos blogs de fotografia dos diários de maior circulação do Brasil

garante o fotógrafo Lauro Alves no FocoBlog em 4 de agosto de 2011. Para conseguir enviar o material da reportagem, "dos grotões" onde se encontrava para a redação do jornal Zero Hora, o fotojornalista criou um "sistema parabólico" com uma tampa de panela (Figura 9).

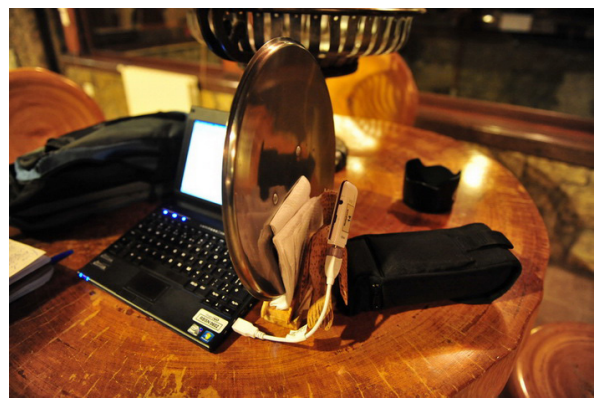

Figura 9 - Post "Quando a Conexão é Ruim, Improvisa-se" Fonte: Botega (2011b).

O outro episódio publicado no blog Diário da Foto em 29 de agosto de 2010, traz Marcelo Oliveira, na época repórter fotográfico do jornal Diário Gaúcho, procurando o melhor ângulo da movimentação nos arredores de uma feira agrícola "em cima de um banquinho emprestado por um dos comerciantes das barraquinhas locais" (Figura 10).

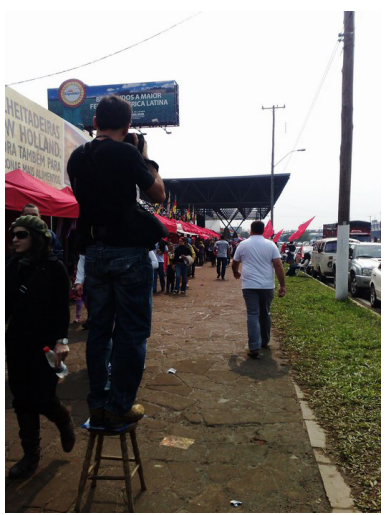


Figura 10 - Post "Em Cima do Lance - e do Banco" Fonte: Vanzella (2010b).

No outro lado do mundo, fotógrafo oficial do Qatar encontra o melhor ângulo para a realização da foto em meio aos destroços no subúrbio da Líbia. A imagem que traz o fotógrafo em cima de um carro destruído foi publicada no blog Olhar sobre o Mundo em 2011 (Figura 11). A manobra para conseguir o ângulo certo evidencia que o foco do fotografo está na realização das imagens que melhor definam os acontecimentos, mesmo que para conseguilas eles tendam a ignorar a própria condição ao redor.

Figura 11 - Post "Testemunhas Oculares da História"

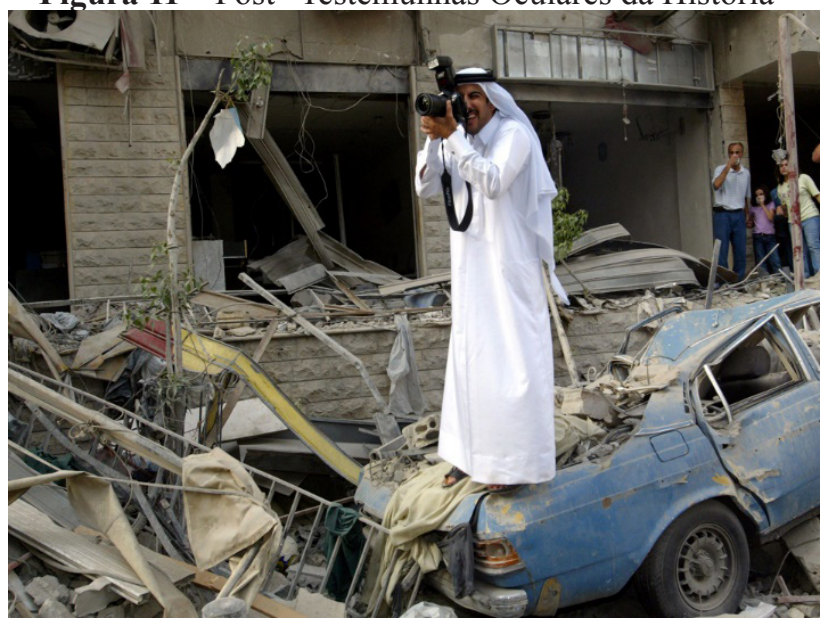

Fonte: Olhar sobre o Mundo (2011).

Face ao exposto, os fotojornalistas, ao postarem conteúdos nos blogs, acabam repetidas vezes realizando monitoramentos das rotinas profissionais e mobilizando saberes mútuos e compartilhados entre seus pares; ora tentando extrair-lhes regras, ora deixandose levar por elas, conforme já apontado anteriormente. Na teoria da estruturação de Giddens (2003, p. 3), novamente, o princípio das ações humanas requer reflexividade, entendida não somente como autoconsciência, "mas como o caráter monitorado do fluxo 
contínuo da vida social." Isso quer dizer que a descrição das práticas só é possível caso os sujeitos manifestem familiaridade com elas através de sua realização continuada. Essa recorrência ou "ordenação recursiva" (GIDDENS, 2003) num espaço-tempo determinado, torna-se condição indispensável para que os sujeitos estejam aptos a formular descrições/reflexões sobre suas práticas. Além disso, o monitoramento reflexivo da atividade, segundo Giddens (2003), envolve a conduta não apenas do indivíduo, mas também de seus pares. Concomitantemente, os sujeitos mantêm "um contínuo entendimento teórico das bases de sua atividade" (GIDDENS, 2003, p. 9) e formulam orientações em nome de um grupo social ao qual pertencem ou estão ligados.

Fausto Neto (2010) vai nomear as operações autorreflexivas sobre os modos de ser jornalístico e as práticas de seus atores de "realidade da construção". Apesar de não incorporar os blogs em sua análise, podemos desdobrar as considerações de Fausto Neto (2010, p. 124) para pensar porque as próprias rotinas do campo, e de seus atores, estão sendo "transformadas em acontecimento". Para ele, mais uma vez, a estratégia faz parte da tentativa de chegar mais próximo aos leitores/internautas e, sobretudo, serve de fundamento para a constituição do ethos jornalístico e da autonomia do campo, ao colocar em cena, por meio de materialidades discursivas, os elementos que constituem as dinâmicas no interior do jornalismo (FAUSTO NETO, 2010, p. 124-125).

Não por acaso, os fotojornalistas desconhecidos do grande público passam a usar o espaço dos blogs para, literalmente, "mostrar a cara". Servem de exemplo as postagens realizadas no FocoBlog e no Diário da Foto entre os anos de 2009 a 2012, cujas imagens enquadram os fotógrafos dentro e fora do espaço das redações (Figuras 12 a 17). Para o editor de fotografia de Zero Hora, Jefferson Botega, tais momentos se configuram em "oportunidades únicas para fotografar quem sempre está atrás das câmeras" (TP FocoBlog, 01/10/2012). Em tais imagens, os fotorepórteres se perfilam como num time de futebol, mostrando que o senso de 
coletividade passa pela ideia de "equipe" ligada não pela instituição a qual trabalham, mas pelo exercício da profissão.

Figura 12- Post "Profissionais do Fotojornalismo Esportivo"

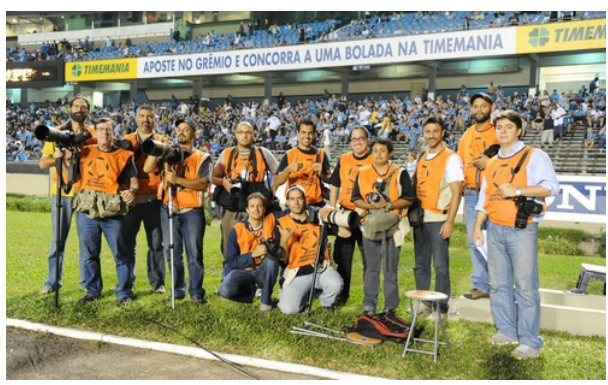

Fonte: Botega (2009b).

Figura 13 - Post "Foto Oficial"
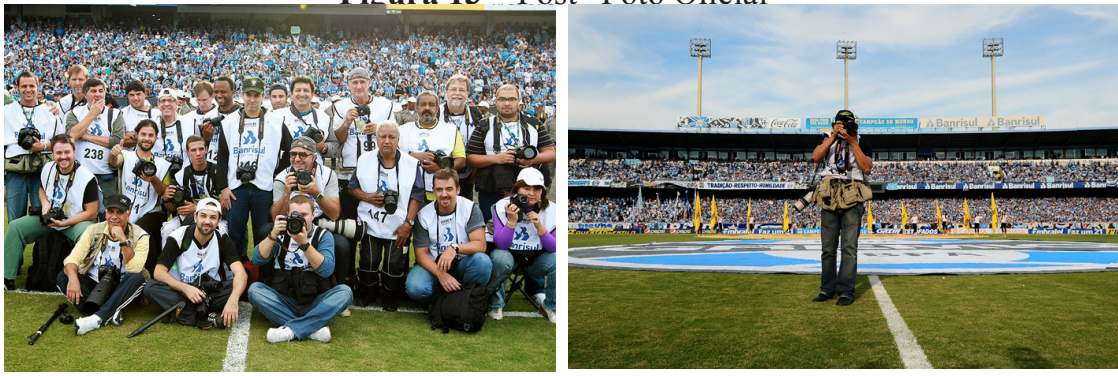

Fonte: Botega (2010).

Figura 14 - Post "Fotografia zh"

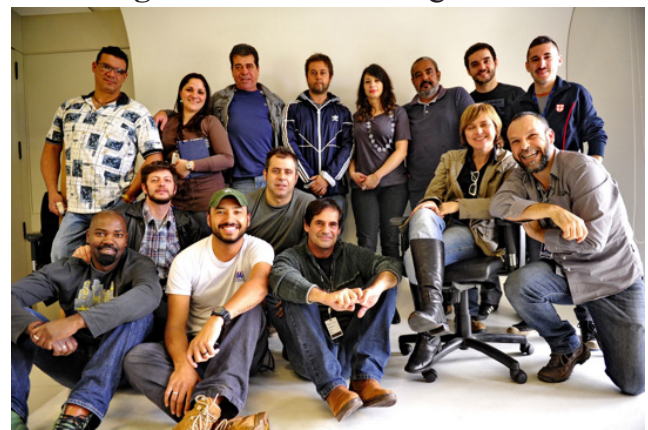


78 Indícios dos modos de produção fotojornalísticos nos blogss de fotografia dos diários de maior circulação do Brasil

Fonte: Alencastro (2012).

Figura 15 - Post "Bom Dia”

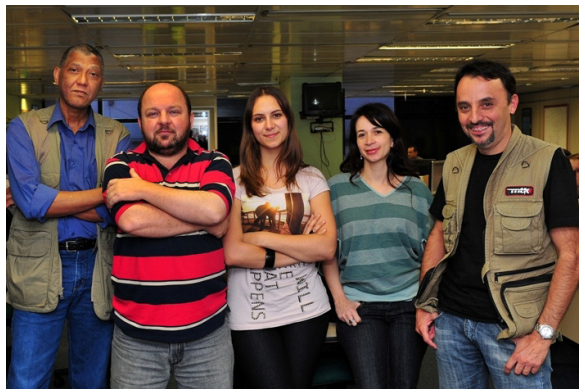

Fonte: Feltes (2010a).

Figura 16 - Post "Porto Alegre Vai Cair no Samba" Fonte: Macedo (2012).

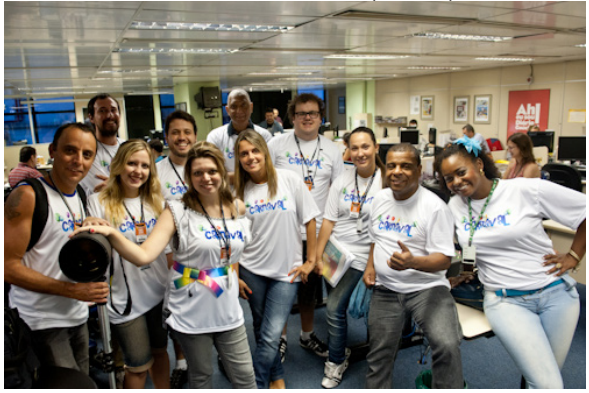

Figura 17 - Post "Profissão Repórter Fotográfico" Fonte: Olhar sobre o Mundo (2010b).

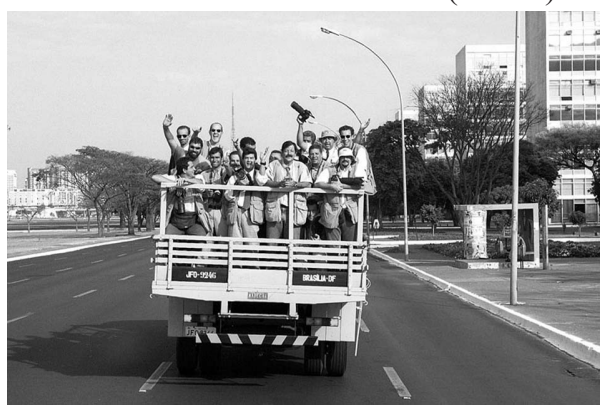


Sendo assim, ao lançar mão de um discurso autorreferente, começa-se a observar também mudanças no protocolo jornalístico, o que tem contribuído para a ampliação do conhecimento das atividades produtivas e legitimação do campo, mas que, em última instância, visa à retomada da credibilidade social.

No entanto, alguns autores irão elencar as aptidões necessárias para que um "simples" fotógrafo se torne um "repórter fotográfico". Tais qualidades são, na maioria dos casos, forjadas na prática da fotografia jornalística. De acordo com a experiência adquirida nos vários anos em que ministra cursos sobre fotojornalismo, Castellanos (2003), por exemplo, compilou dez características que considera indispensáveis ao bom repórter fotográfico: 1) Interesse por fotografia; 2) domínio técnico; 3) sensibilidade visual; 4) cultura geral e informação; 5) manutenção e superação dos sucessos diários; 6) sentido de oportunidade; 7) capacidade de síntese; 8) total disponibilidade; 9) ética; 10) experiência em projetos individuais (CASTELLANOS, 2003, p. 110-111).

Embora bem abrangente, acreditamos que a lista proposta pelo autor espanhol se mostra incompleta, na medida em que não contempla algumas especificidades solicitadas aos profissionais da imagem pelas empresas jornalísticas a partir da adesão às tecnológicas digitais, como a capacidade de atuação em diferentes plataformas, por exemplo. A emergência de outros mediadores, usos e instrumentos de captação, tratamento e difusão da fotografia jornalística modificaram o desenho tradicional do departamento nas redações. Sendo assim, a entrada de figuras como o "editor de vídeo", o "assistente de conteúdo" ou os "tratadores de imagens", configurariam os novos meios de acessar e trabalhar a imagem nos jornais $^{5}$, já que alguns periódicos oriundos do impresso possuem,

5 Alonso (2011, p. 93-119) vai apresentar em sua dissertação de mestrado o que considera serem as funções emergentes no jornalismo brasileiro: o "jornalistaprogramador"; o "jornalista especialista em banco de dados"; o "gestor/editor de mídias sociais"; o "jornalista multimídia"; o "produtor web" e, por fim; o "jornalista empreendedor". 
80 Indícios dos modos de produção fotojornalísticos nos blogs de fotografia dos diários de maior circulação do Brasil

hoje, até canais de televisão na web. Segundo Ramón Salaverría e Samuel Negredo (2008), o fotojornalista foi um dos primeiros profissionais a que se exigiu ser "multimídia", levando-os a se conformar rapidamente à nova realidade 6 . Pedroso (2008, p. 47) ainda aponta um exemplo da atual rotina dos repórteres fotográficos na transmissão de imagens esportivas:

Essa nova rotina é facilmente observável em jogos de futebol de importância, por exemplo, onde os fotógrafos fotografam com seus lap-tops abertos e, enquanto a bola vai para o outro lado do campo, tratam de editar e enviar o material recém obtido para alimentar seus veículos quase que instantaneamente (PEDROSO, 2008, p. 47).

Coincidência ou não, a imagem publicada na postagem de 17 de junho de 2009 no FocoBlog ilustra, justamente, a situação descrita por Pedroso (2008), com fotógrafos transmitindo imagens pelo computador direto do estádio (Figura 18).

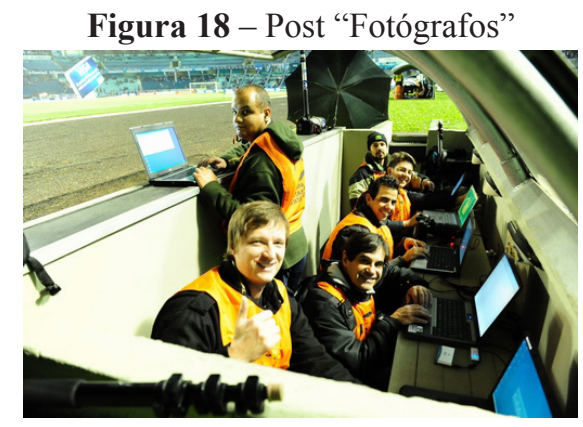

6 A digitalização e a convergência das plataformas dos veículos de comunicação também podem ser apontadas como causas da precarização das condições de trabalho dos jornalistas, que se sentem obrigados a assumir papéis e funções adicionais, como adaptarem conteúdos aos formatos digitais, sem receberem a mais por isso, diminuindo o número médio de jornalistas por empresas do ramo. Além disso, a conectividade generalizada mantém os jornalistas em contato praticamente ininterrupto com seu público, muitas vezes fazendo horas extras a partir de casa ou de seus horários de folga. 
Fonte: Botega (2009a).

Responsáveis por diminuir o tempo de captação e circulação, além de potencializar o aumento da publicação de imagens feitas por qualquer pessoa ${ }^{7}$, portanto, as tecnologias digitais retiraram do fotógrafo o monopólio do saber fotojornalístico, acarretando o retorno da disputa entre profissionais e diletantes. Podemos perceber, face ao exposto, a existências de uma luta simbólica (BOURDIEU, 2007) entre fotógrafos profissionais e àqueles considerados amadores, ou seja, mecanismos que engendram conflitos de competência que se opõem para garantir o reconhecimento de uma posição ou campo. Neste sentido, o domínio autorizado da capacidade de "melhor contar histórias" dá direito aos fotojornalistas do exercício legítimo da profissão. A aptidão material e simbólica de determinadas características os tornaria "naturalmente" melhores que qualquer outro indivíduo no desempenho das mesmas funções.

Porém, Sorlin (2004, p. 71) acredita ser cada vez mais necessária a figura do profissional como "sinônimo de excelência", servindo de parâmetro de desempenho; como "espejo del aficcionado" (SORLIN, 2004, p. 96). Neste sentido, as imagens produzidas pelos amadores nada mais seriam que reproduções das fotografias que circulam na imprensa diariamente, cujos padrões normativos são estabelecidos pelos próprios fotojornalistas (SORLIN, 2004).

As postagens a seguir nos servem para identificar as marcas da atual conjuntura. Nelas, os repórteres fotográficos descrevem os "truques" utilizados na captação de determinadas imagens, atrelando o domínio da técnica à aptidão profissional. Os modos como seguram a câmera, como se posicionam para conseguir determinados enquadramentos, além dos "macetes" técnicos, demonstram a crença de que o "verdadeiro" fotógrafo é aquele que possui domínio total sobre a produção de suas imagens. São recursos

7 A solicitação cada vez maior do público na elaboração da notícia torna ainda mais porosa a fronteira entre "profissional" e "amador". Com ela, as empresas jornalísticas objetivam tanto a ampliação audiência, como a redução dos custos de produção. 
82 Indícios dos modos de produção fotojornalísticos nos blogs de fotografia dos diários de maior circulação do Brasil

utilizados pelos profissionais "naturalmente aptos para este tipo de atividade", conforme consta no blog Diário da Foto em 6 de julho de 2010 (Figura 19). A imagem que abre a postagem, de autoria de Ivan Sekretarev (Associated Press), traz em primeiro plano a bola de futebol no momento em que toca as redes do gol; enquanto que, num segundo plano, à esquerda, há um jogador comemorando e, à direita, aparece o goleiro caído. Na sequência, outras três imagens são publicadas para "explicar” a primeira.

A repórter fotográfica do jornal Diário Gaúcho na época, Cynthia Vanzella, descreve como foi possível conseguir tal ângulo de captação: "a cada partida, cerca de 20 fotógrafos são escolhidos para colocar suas câmeras neste local privilegiado. Depois, ficam posicionados nas laterais do campo e acionam as câmeras com a ajuda de cabos ou rádios transmissores". E finaliza: "Com muita atenção e um pouco de sorte, conseguem captar imagens fantásticas". A postagem ainda traz o depoimento do repórter fotográfico da Agência Estado, Jonne Roriz, que relata que "quase diariamente uma câmera é atingida por uma bolada. O impacto destrói o equipamento e deixa a lente em pedaços. Mas é o preço que se paga para ter a imagem de um ângulo em que não se pode estar fisicamente".

Figura 19 - Post "Close na Jabulani"
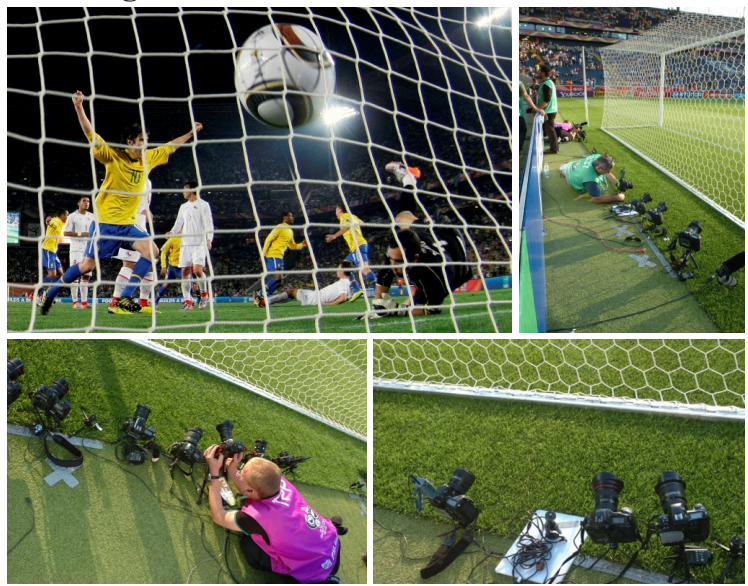
Fonte: Feltes (2010b).

Tanto o post acima, quanto os que virão a seguir, pertencem a seção "Bastidores" do blog Diário da Foto. Nesta categoria, as postagens invariavelmente mostram os fotógrafos em ação junto aos resultados obtidos, numa espécie de "tutorial" da imagem fotográfica (Figuras 20, 21, 22 e 23). Neste cenário, a tentativa de conter o "ataque" emergente dos amadores com seus aparelhos celulares cada vez mais potentes e conectados, portanto, parece fazer da experiência e da polivalência dos repórteres fotográficos os sustentáculos últimos da profissão.

Figura 20 - Post "500 Sorrisos no Próximo dia 12"

$\mathrm{O}$ momento da captação/O resultado

Fonte: Vanzella (2010a).
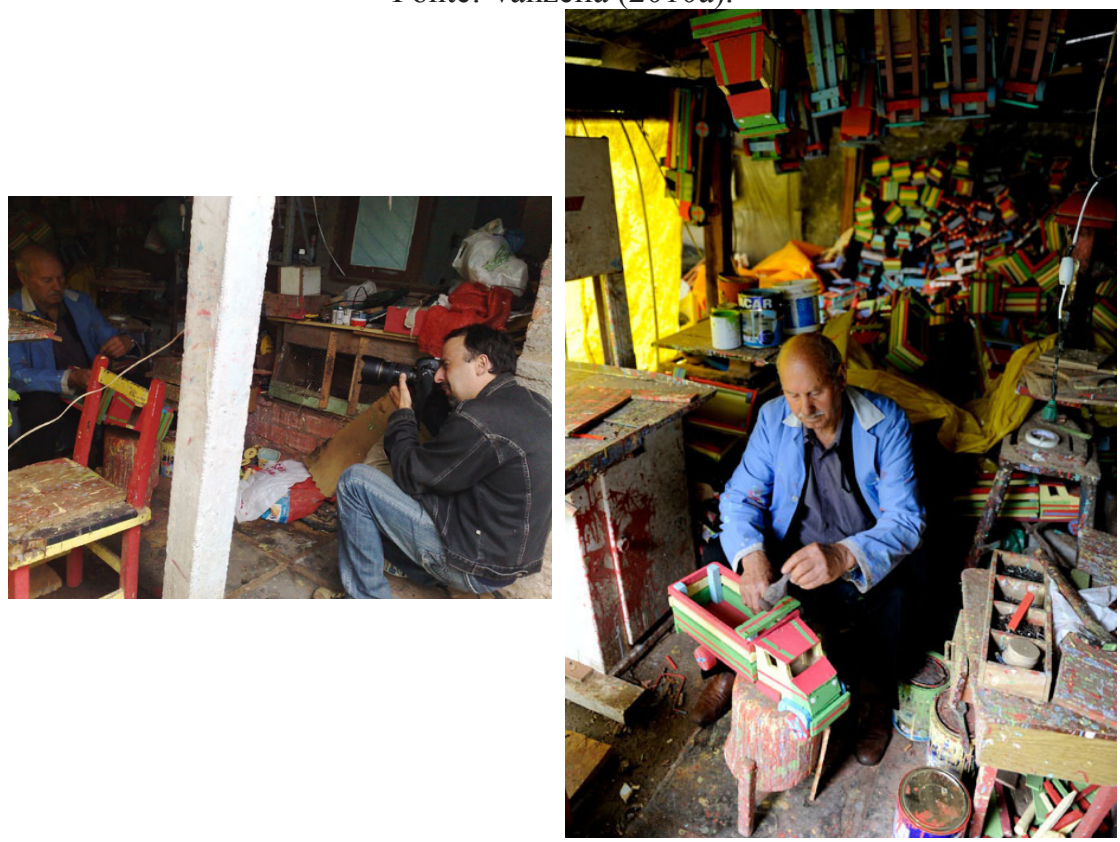
84 Indícios dos modos de produção fotojornalísticos nos blogss de fotografia dos diários de maior circulação do Brasil

Figura 21 - Post "Esforço em Equipe"

O momento da captação/O resultado

Fonte: Vanzella (2010c).
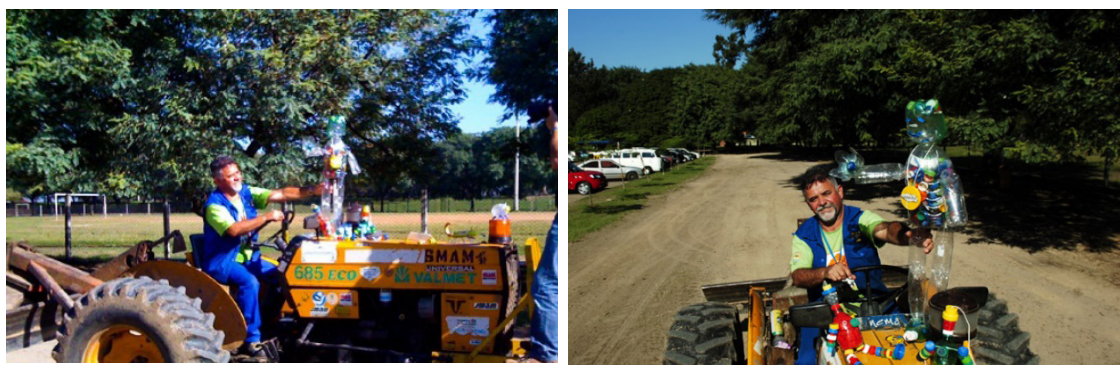

Figura 22 - Post "Muito Obrigado, Povo da Copa!"

$\mathrm{O}$ momento da captação/O resultado

Fonte: Bruxel (2014).
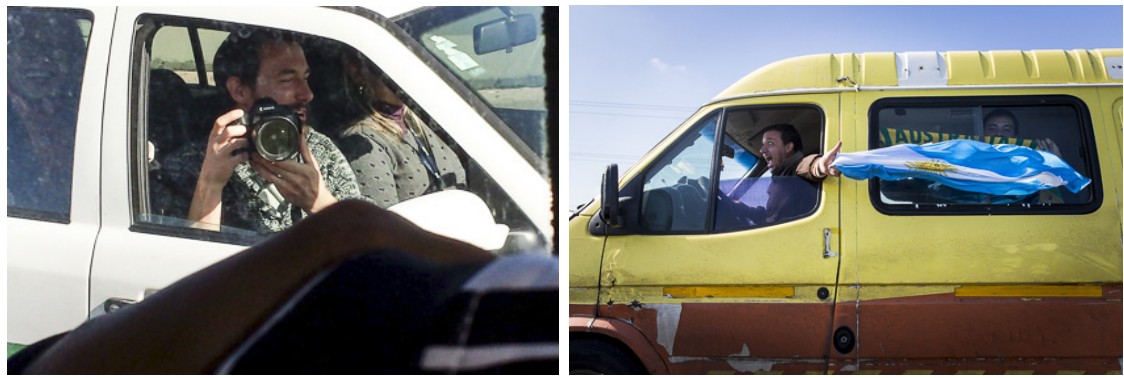

Figura 23 - Post "Foto da Foto"

O momento da captação/O resultado

Fonte: Vanzella (2010d).
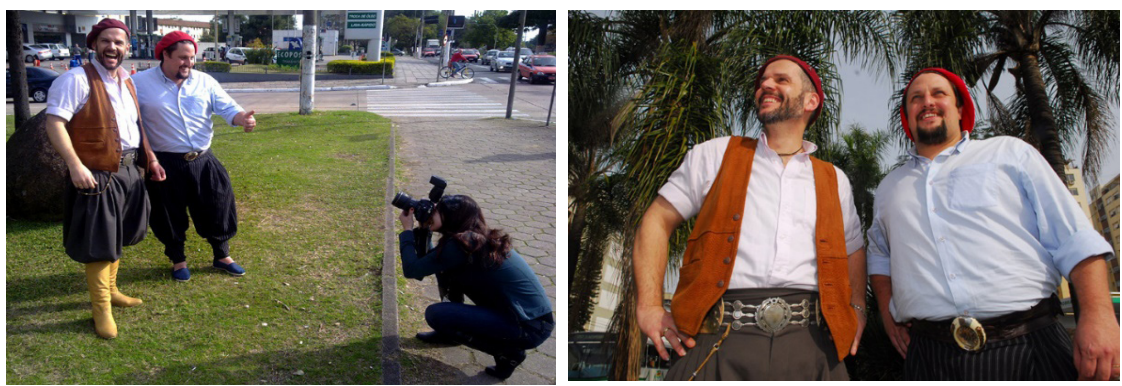


\section{Em busca da legitimação do campo da fotografia jornalística}

No contexto dessas articulações, afinal, é possível definir o repórter fotográfico e seu trabalho? Basicamente, o conjunto de postagens e suas respectivas imagens mostram que a prática da fotografia jornalística obedece a critérios formulados pelos próprios profissionais enquanto realizam de forma regular suas atividades, operação que Giddens (2003) batizou de consciência discursiva. Já nesta primeira aproximação foi possível perceber que, ao lançarem luz sobre a própria práxis nestas plataformas, tais profissionais tem incorporado lógicas autor-referenciais, tornando-as estratégias capazes de delimitar o campo de atuação e de estabelecer um novo vínculo de interação com o leitor. Ou seja, ao focar nos produtores de imagem da e para a imprensa, os fotojornalistas que contribuem com os blogs de fotografia acabam, sobretudo, descrevendo as técnicas, geralmente desconhecidas, que orientam e justificam seu trabalho. A visibilidade e a descrição de tais procedimentos acabam por refletir numa maior audiência, que marca tanto o conteúdo, quanto à forma das fotografias; tanto as ações, quanto as reflexões de cada fotógrafo sobre sua atuação.

No bojo desta construção, podemos considerar o fotojornalismo não só como profissão ou saber específico, mas como uma comunidade interpretativa, responsável por partilhar um senso-comum da atividade, interpretando-a coletivamente. Tanto as imagens quanto os comentários dos fotojornalistas sobre suas práticas parecem querer alcançar o senso comum que os liga, uma compreensão partilhada sobre suas técnicas profissionais que os une enquanto grupo ou categoria.

Esse conjunto de postagens apresentados acima deixa evidente, ao fim e ao cabo, que a reflexão sobre as rotinas de produção das imagens jornalísticas obedece a critérios não estabelecidos formalmente pelas instituições, mas coordenados pela experiência e interpretação de um grupo. Os blogs de fotografia dos 
86 Indícios dos modos de produção fotojornalísticos nos blogs de fotografia dos diários de maior circulação do Brasil

jornais brasileiros, portanto, não são somente espaços de orientação sobre as práticas, mas também dispositivos de autorreflexão e monitoramento reflexivo das ações, transmutando-se, muitas vezes, um uma base deontológica não institucionalizada para o desempenho do fotojornalismo profissional.

\section{Referências}

ALENCASTRO, Bruno Fotografia ZH. FocoBlog, 1 out. 2012.

Disponível em: <http://wp.clicrbs.com.br/focoblog/2012/10/01/ fotografia-zh/?topo=13,1,1,„,13>. Acesso em: 13 fev. 2015.

ALONSO, André Deak. Novos jornalistas do Brasil. 2011. 148

f. Dissertação (Mestrado em Comunicação) - Universidade de São Paulo, São Paulo, 2011.

ALVES, Lauro. Não vai mudar tanto assim. FocoBlog, 21 out. 2011. Disponível em: <http://wp.clicrbs.com.br/focoblog/2011/10/21/ nao-vai-mudar-tanto-assim/?topo=13,1,1,„13>. Acesso em: 13 fev. 2015.

BOTEGA, Jefferson. Drama das cheias em imagens. FocoBlog, 14 jul. 2015. Disponível em: <http://wp.clicrbs.com.br/ focoblog/2015/07/14/9807/?topo=13,1,1,,,13>. Acesso em: 13 nov. 
2015.

BOTEGA, Jefferson. Foto oficial. FocoBlog, 3 maio 2010. Disponível em: http://wp.clicrbs.com.br/focoblog/2010/05/03/ foto-oficial/?topo=13,1,1,,13>. Acesso em: 13 fev. 2015.

BOTEGA, Jefferson. Fotógrafos e cinegrafistas desaparecidos na Líbia. FocoBlog, 18 mar. 2011a. Disponível em: <http:// wp.clicrbs.com.br/focoblog/2011/03/18/fotografos-e-cinegrafistasdesaparecidos-na-libia/?topo $=13,1,1,, 13>$. Acesso em: 13 fev. 2015

BOTEGA, Jefferson. Fotógrafos. FocoBlog, 17 jun. 2009a. Disponível em: <http://www.clicrbs.com. br/blog/jsp/default.jsp?source=DYNAMIC,blog. 